\title{
Síndrome de enclaustramiento secundario a desmielinización osmótica. Importancia de la resonancia magnética en su diagnóstico
}

\section{Locked-in Syndrome Caused by Osmotic Demyelination Syndrome. The Importance of Magnetic Resonance Imaging in Diagnosis}

\author{
E. A. Gamarra Avilés ${ }^{1} \quad$ N. Guazzaroni ${ }^{1}$ \\ M. Meso $^{2}$ \\ F. Tomasco 2 \\ S. Barragan ${ }^{2}$
${ }^{1}$ Servicio de Resonancia magnética, Hospital Italiano La Plata, Buenos Aires, Argentina
2 Servicio de Clínica Médica, Hospital Interzonal Especializado de Agudos y Crónicos Dr. Alejandro Korn, La Plata, Buenos Aires, Argentina

Rev Argent Radiol 2018;82:42-44.

\author{
$\begin{array}{lll}\text { B. Pievani } & \text { I. Cueto Rúa } & \text { L. E. Musurguan }\end{array}$
}

Address for correspondence Dr. Emmanuel Alejandro Gamarra Avilés, MD, Calle $55 N^{\circ} 416$ piso 7 depto. B. CP 1900 Hospital Italiano La Plata, Buenos Aires, Argentina (e-mail: emmanuelgamarra@hotmail.com).

neurológico de pacientes alcohólicos y malnutridos. Otras causas posibles son el uso prolongado de diuréticos, sepsis, quemaduras extensas, fallo hepático y trasplantes bajo tratamiento inmunosupresor. Esos pacientes desarrollan cuadriplejía espástica, parálisis pseudobulbar o encefalopatía.

En 1962, se comunicó la posibilidad de aparición de la entidad fuera de la protuberancia, condición que fue denominada "mielinólisis extra pontina" (MEP). Ella ocurre en el 10-50\% de los casos de mielinólisis osmótica. ${ }^{6}$ Los sitios de afección incluyen los ganglios de la base, el tálamo, la sustancia blanca cerebral $\mathrm{y}$, menos frecuentemente, la corteza periférica y el hipocampo.

El término síndrome de desmielinización osmótica (SDO) se utiliza cuando ambas entidades están presentes en el mismo paciente. Dado que las vías sensitivas y la conciencia pueden permanecer indemnes, es posible que los pacientes desarrollen un $\mathrm{SE}^{5}$

Clásicamente se desarrolla por la corrección rápida de una hiponatremia. El mecanismo de mielinólisis relacionado con el estrés osmótico es desconocido. ${ }^{7}$ Se considera que los cambios en la osmolaridad sérica causan una alteración de la barrera hematoencefálica, que produce la acumulación de líquido hipertónico en el espacio extracelular. Eso genera una desmielinización no inflamatoria extensa. ${ }^{6}$

Copyright $\odot$ 2019, Sociedad Argentina de Radiología. Publicado por Thieme Revinter Publicações Ltda., Rio de Janeiro, Brazil. Todos los derechos reservados.

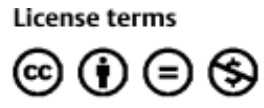

DOI https://doi.org/

10.1055/s-0038-1637032. ISSN 1852-9992. accepted

July 11, 2017

published online

March 23, 2018 
Los hallazgos radiológicos típicos del SDO se desarrollan en la primera o segunda semana del inicio del cuadro clínico. ${ }^{8}$

Nuestro objetivo es describir las características por resonancia magnética (RM) del SE secundario al SDO, dada su baja prevalencia y su importancia en la comprobación diagnóstica. Para ello, presentamos el caso de una mujer de 61 años de edad, con antecedente de hipertensión arterial y en tratamiento con hidroclorotiazida, que consultó a la guardia por presentar confusión e inestabilidad de la marcha, con una hiponatremia de $103 \mathrm{mEq} / \mathrm{l}$. Se inició corrección con solución de cloruro de sodio (ClNa) al 3\% y la paciente evolucionó con normalización de los valores de natremia dentro de las 72 horas. Sin embargo, tras una franca mejoría inicial, desarrolló a los 7 días cuadriparesia progresiva, disartria y finalmente disfagia.

Se solicitó una tomografía computada (TC) de encéfalo con contraste, que no evidenció signos de isquemia ni colecciones hemáticas espontáneamente visibles. Ante la progresión del cuadro clínico, a los 15 días de su inicio, se realizó una RM de encéfalo con gadolinio. En ella se destacó, como hallazgo principal, hiperintensidad a nivel de la porción central de la protuberancia, los ganglios de la base y ambos tálamos en secuencias ponderadas en $\mathrm{T} 2$ y recuperación de inversión atenuada deflujo (FLAIR), e hipointensidad en ponderación T1, con restricción en la técnica de difusión ( - Figs. 1 y 2). Esos hallazgos eran compatibles con MPC y MEP.
La paciente evolucionó clínicamente con SE y finalmente falleció por complicaciones infecciosas.

La TC es mucho menos sensible que la RM para el diagnóstico por imágenes del SDO, ya que la protuberancia puede mostrarse hipodensa por artefacto del hueso petroso cercano. Las áreas afectadas por mielinólisis suelen identificarse como lesiones hipodensas en el estudio sin contraste, reflejando edema. ${ }^{6}$ La TC con contraste muestra ausencia de refuerzo. ${ }^{7}$

Los hallazgos característicos en RM se observan en secuencias ponderadas en T2 y FLAIR. Durante la fase aguda se aprecia hiperintensidad simétrica en la protuberancia central, con forma de tridente, respetando la periferia, las vías corticoespinales (MPC) y los ganglios de la base (MEP). ${ }^{7,8}$ En secuencias ponderadas en T1 se visualiza el área afectada con una disminución en la intensidad de señal sin efecto de masa. En imágenes de difusión se identifica una restricción en la movilidad de las moléculas de agua en la fase aguda con la consecuente disminución de intensidad en el coeficiente de difusión aparente. La restricción a la difusión puede hacerse evidente con áreas de mielinólisis a las 24 horas del inicio de los síntomas. ${ }^{8}$

La espectroscopia por RM puede demostrar una disminución del índice N-acetil-aspartato (NAA)/creatinina (Cr) y un aumento del índice colina (Cho)/Cr. La RM de perfusión puede exhibir aumento de la perfusión en los mapas de volumen sanguíneo cerebral. ${ }^{6}$

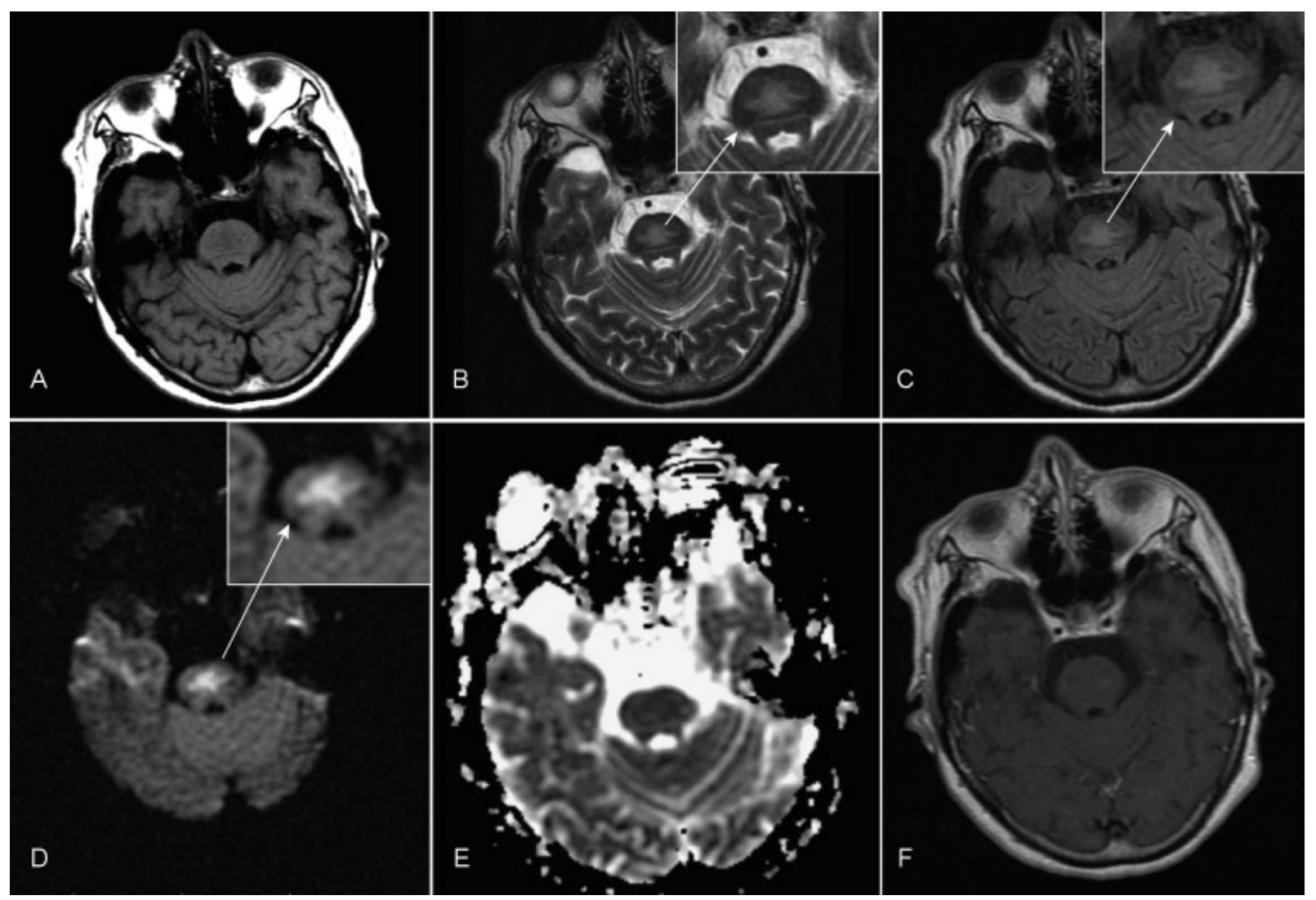

Fig. 1 RM cerebral con contraste, en cortes axiales, muestra (A) hipointensidad en la región central de la protuberancia en secuencia ponderada T1, (B) hiperintensidad simétrica en la protuberancia central en forma de tridente (flechas) en ponderación T2, (C) imágenes en FLAIR, (D) con restricción a la difusión de las moléculas de agua y (E) su correspondiente mapa de coeficiente de difusión aparente (ADC), además de (F) imágenes sin realce con contraste endovenoso. 


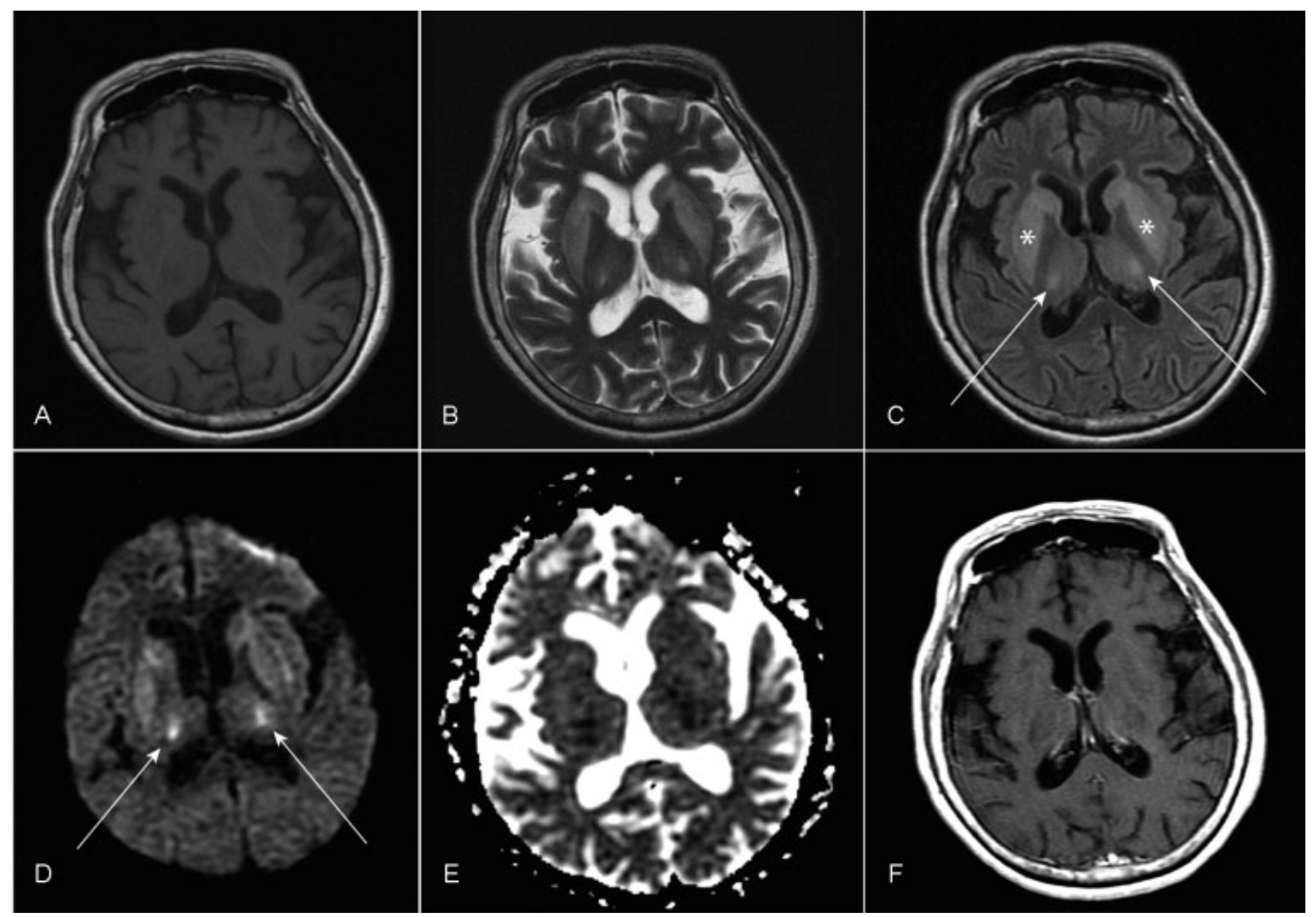

Fig. 2 RM cerebral con contraste, en cortes axiales, evidencia disminución en la intensidad de señal bilateral en la cabeza del núcleo caudado, núcleo lenticular y tálamo de forma bilateral en la secuencia ponderada enT1 (A), hiperintensidad de señal simétrica en ganglios basales y tálamo en ponderación T2 (B) y FLAIR (C), además presentan restricción de la difusión (D) y su equivalente mapa de ADC (E), sin refuerzo poscontraste endovenoso (F). Ganglios basales: asteriscos. Tálamo: flechas.

Los diagnósticos diferenciales principales son patología isquémica (compromiso anteromedial de borde recto) y tumoral (efecto de masa).

Como conclusión, es necesario destacar el importante rol de la RM por su mayor sensibilidad que la TC y los hallazgos radiológicos característicos para el diagnóstico de mielinólisis osmótica como causa de SE.

Los saludan a ustedes, con distinguida consideración, los autores.

Confidencialidad de los datos

Los autores declaran que han seguido los protocolos de su centro de trabajo sobre la publicación de datos de pacientes y que todos los pacientes incluidos en el estudio han recibido información suficiente y han dado su consentimiento informado por escrito para participar en dicho estudio.

\section{Conflicto de Intereses}

Los autores del trabajo declaran no tener ningún conflicto de intereses.

\section{Bibliografía}

1 Collado-Vázquez S, Carrillo JM. El síndrome de cautiverio en la literatura, el cine y la televisión. Rev Neurol 2012;54:546-570

2 Sandoval P, Mellado P. Síndrome de Locked- in. En: AA.VV. Cuaderno de neurología. Vol XXIV. Pontificia Universidad Católica de Chile: Santiago de Chile; 2000. Disponible en: http://publicacionesmedicina. uc.cl/cuadernos/2000/pub_16_2000.html

3 Lara Reyna J, Burgos Morales N, Achi Arteaga J, Martínez Neira D, Cárdenas Mera B. Síndrome de enclaustramiento. Presentación de un caso. Rev Chil Neurocirugía 2015;41:124-126

4 Luján-Ramos VP, Monterrosa Salazar E, Polo Verbel L. Síndrome de enclaustramiento: a propósito de un caso. Rev Cinc Biomed 2011; 2:116-120

5 Riquelme Sepúlveda V, Errázuriz Puelma J, González Hernández J. Síndrome de enclaustramiento: caso clínico y revisión de la literatura. Revista Memoriza Com 2011;8:1-9

6 Huang BY. Enfermedades tóxicas y metabólicas del cerebro. En: Naidich TP, Castillo M, Cha S, Smirniotopoulos JG, eds. Imagenología del cerebro. Caracas: Amolca; 2017:951-952

7 Osborn AG, Salzman KL, Barkovich AJ. Diagnóstico por imagen: Cerebro. Madrid: Marbán; 2011:54-57

8 Howard SA, Barletta JA, Klufas RA, Saad A, De Girolami U. Best cases from the AFIP: osmotic demyelination syndrome. Radiographics 2009;29(03):933-938 